\title{
LEITURAS SOBRE EDUCAÇÃO E NEOLIBERALISMO
}

\author{
READINGS ABOUT EDUCATION AND NEOLIBERALISMO
}

\section{LECTURAS SOBRE EDUCACIÓN Y NEOLIBERALISMO}

\author{
Giovanna Dalquiavon ${ }^{1}$ \\ https://orcid.org/0000-0002-4065-5613 \\ Junior Bufon Centenaro ${ }^{2}$ \\ https://orcid.org/0000-0003-3046-3885 \\ Thalia Leite de Faria ${ }^{3}$ \\ https://orcid.org/0000-0001-8950-9564
}

\begin{abstract}
${ }^{1}$ Universidade de Passo Fundo, Marau, Rio Grande do Sul - Brasil. E-mail: 177122@upf.br.
${ }^{2}$ Universidade de Passo Fundo, Marau, Rio Grande do Sul - Brasil. E-mail: junior.centenaro@bol.com.br.

${ }^{3}$ Universidade de Passo Fundo, Marau, Rio Grande do Sul - Brasil. E-mail: 159152@upf.br.
\end{abstract}

A coletânea Leituras sobre Educação e Neoliberalismo (2020), publicada pela Editora CRV e organizada por Altair Alberto Fávero, Carina Tonieto e Evandro Consaltér, tem por objetivo socializar reflexões acerca das implicações do neoliberalismo na educação. Resultado de estudos junto ao Grupo de Estudos e Pesquisas em Educação Superior (GEPES), da Universidade de Passo Fundo (UPF), conta com a participação de pesquisadores da Universidad Autónoma del Estado de México (UAEMéx), da Universidad de Colima (UCOL/México) e da Faculdade de Psicologia e Ciências da Educação da KU Leuven, na Bélgica. Participam também pesquisadores do Grupo Internacional de Estudos e Pesquisas sobre Educação Superior da Universidade Estadual de Campinas (GIEPES/UNICAMP) e da Rede de Estudos e Pesquisas sobre Educação Superior (REPES/FURG). A coletânea possui 22 capítulos de autores nacionais e internacionais que refletem acerca das problemáticas advindas da incursão do neoliberalismo na educação. 
O primeiro capítulo da coletânea, intitulado "Eficácia ou proselitismo? A escola sob os ditames do gerencialismo empresarial", assinado pelos autores e também organizadores da coletânea Altair Alberto Fávero, Carina Tonieto e Evandro Consálter, analisa a questão das relações entre público e privado na educação básica e seus impactos negativos, fruto da retórica advinda da perspectiva empresarial que aponta que a escola poderia gerar melhores resultados quando gerenciada pelo modelo empresarial.

O segundo capítulo, que tem por título, "Con rebajas y a precio de costo, la educación superior como consumo: expresiones de un cotidiano universitario", dos autores mexicanos Aristeo Santos López e Marisa Fátima Roman, reflete acerca da ciência, da tecnologia e do processo de globalização em prol do mercado no contexto da educação superior. Para os autores, na educação superior tem se intensificado a concepção de que o ambiente acadêmico seja regido pela lógica da produtividade, quantidade e lucro sobre o conhecimento por meio de uma gestão estrutural que vai ao encontro desse ideal.

O texto denominado Citizenship education policy in europe and its normativity: building vs. bildung?, que tem como autora a pesquisadora Margot Joris, da Katholieke Universiteit Leuven, Bélgica, elucida a questão da educação para cidadania nas escolas no contexto europeu, evidenciando como tal questão tem guiado propostas dentro das políticas educacionais europeias que visam à contribuição do ensino na construção do país. A autora sustenta como a promoção de uma educação voltada a esse aspecto pode tornar-se ambígua, quando as políticas não tornam claros os conceitos envoltos. Um exemplo ilustrativo é a confusão entre os termos alemães building e bildung, construção e formação, respectivamente. Para a autora, é fundamental compreender a diferença entre ambos.

O quarto capítulo da obra tem autoria de Gabriele Borinelli e Monica Ribeiro da Silva, tendo por título "Parcerias público-privadas e disponibilização de recursos financeiros para institutos e fundações privadas no contexto da reforma do Ensino Médio". O texto analisa a regulamentação das parcerias público-privadas segundo os documentos normativos apontados durante o governo Temer. Em seguida, as autoras refletem acerca das consequências dessas leis que guiam um projeto de privatização, promovendo como efeito o mercado atuando como medida de qualidade por um processo de empresariamento.

De autoria de Angelo Vitório Cenci, o quinto capítulo, intitulado "Neoliberalismo, capital humano e educação", busca compreender a fase atual do neoliberalismo, tendo como 
pressuposto que a teoria do capital humano serve de sustentação para a concepção de neoliberalismo que tem permeado a educação. Dessa forma, o autor aborda a dimensão "hiperautoritária" do neoliberalismo como um modo de "ser no mundo e de interpretar o mundo" (p. 91), em que atua como "estado de exceção". Versa sobre o sentido amplo do neoliberalismo como uma racionalidade, ultrapassando a visão de que se trata apenas de um modelo econômico ou sistema político.

Em seguida, o sexto capítulo, denominado "Educação: conhecimento e pedagogia das competências", dos pesquisadores Jerônimo Sartori e Leandro Carlos Ody, propõe uma reflexão sobre a educação por meio de uma análise da Base Nacional Comum Curricular (BNCC), enfatizando a abordagem das competências. Os autores buscam articular a crítica à concepção de competências de Laval (2004) com a compreensão de competências inerentes à BNCC. Alertam para a descaracterização do papel do conhecimento no desenvolvimento de competências e, para tal, refletem sobre a influência da matriz capitalista baseada nas prerrogativas neoliberais, que servem de base para a valorização da pedagogia por competências no cenário atual da educação básica.

O sétimo capítulo, intitulado "A lógica perversa da profissionalização: a ideologia empresarial invade os processos formativos", é de autoria de Altair Alberto Fávero, Lidiane Limana Puiati Pagliarin e Sidnei Cruz Sobrinho. A pesquisa atém-se às questões acerca das consequências presentes na lógica de profissionalização moldada como uma ideologia que pode produzir processos formativos. Os autores elucidam as discussões em torno do processo de profissionalização das instituições de ensino e a influência de empresas nas universidades, afetando os processos formativos. Apontam, por meio do pensamento de Nussbaum, que a valorização da área das humanidades na educação pode ser um meio de evitar que suas finalidades estejam atreladas somente aos lucros.

Tendo como título "Por una identidad escolar: crítica al espectro empresarial en la educación básica brasileña y mexicana", o texto dos autores Edgar Flores e Evandro Consaltér procura articular as concepções presentes no cenário das educações mexicana e brasileira, demonstrando a forma como a lógica empresarial adentrou os espaços escolares dos países e quais são seus impactos no que diz respeito à identidade escolar amparada no princípio republicano e no bem-estar comum. Os autores analisam de que forma o espectro 
empresarial tem se introjetado na educação brasileira e, em seguida, investigam como esse processo vem ocorrendo no contexto mexicano.

O nono capítulo, de autoria dos pesquisadores Altair Alberto Fávero, Junior Bufon Centenaro e Antônio Pereira dos Santos, tem por título "A cultura humanista como antídoto ao empresariamento da educação: para além da eficiência e da eficácia”. Os autores analisam os conceitos de eficiência e eficácia advindos da linguagem empresarial, que, por sua vez, definem a forma como a escola é pensada na atualidade. O discurso da eficiência e da eficácia limita a formação humana e não proporciona o conhecimento para o cultivo de si e do mundo, fazendo do sujeito um mero produtor que sirva às demandas do mercado. Destacam que a educação deve ser pensada para além dos discursos da lógica empresarial, a partir da noção de cultivo da humanidade, amplamente fundamentado pela filósofa Martha Nussbaum (2005).

O décimo capítulo, de autoria do professor Diego Bechi e intitulado "A responsabilização como mecanismo de empresariamento da educação superior", trata de uma investigação sobre o papel desempenhado pelo princípio toyotista neoliberal da responsabilização como um mecanismo de formação de um novo sujeito, com vistas ao atual cenário da educação superior, que passa por um processo de empresariamento. $\mathrm{O}$ autor trata da responsabilização docente como um mecanismo, tendo a racionalidade capitalista como responsável por produzir um novo modelo de gestão pública. O autor reflete, ao longo do texto, sobre a responsabilização que torna sujeitos gestores de si, a influência de políticas neoliberais globais e as influências negativas da construção de políticas empresariais na educação superior brasileira.

Intitulado "A formação humana no contexto da colonização neoliberal da subjetividade", de autoria de Regiano Bregalda, o décimo primeiro capítulo tem por objetivo criticar a noção de subjetividade neoliberal, marcada pela atomização e pelo individualismo. Ao retomar o conceito de experiência, evidencia um contraponto em relação ao sujeito evocado pelo neoliberalismo pelo viés da formação humana (bildung) que perpassa a noção deweyniana de experiência. Assim, ao criticar o sujeito empresarial neoliberal, apresenta a experiência formativa como alternativa, que se sintetiza pela capacidade de ler o mundo, agir para o bem comum e almejar uma vida democrática.

O décimo segundo capítulo, intitulado "Ideologia neoliberal na educação e a cristalização do novo senso comum pedagógico: quando a educação se torna um negócio”, de 
autoria de Altair Alberto Fávero e Marcio Giusti Trevisol, aborda os conceitos de ideologia neoliberal no âmbito escolar e o sentido de formação de um novo senso comum pedagógico. Para isso trabalham com o referencial de Laval (2004). Em seguida, os autores argumentam que os princípios empresariais passam a ser, também, princípios educacionais. Dessa forma o neoliberalismo produz um novo sujeito, provocando novas relações e um novo senso comum pedagógico. A escola perde seu real sentido enquanto instituição que visa ao desenvolvimento humano, emancipação e senso crítico-reflexivo, aderindo a uma lógica mercantil que oferece uma forma de serviço-cliente.

No décimo terceiro capítulo, "Publicidade infanto-juvenil: a escola enquanto alvo das estratégias de marketing", as autoras Jane Kelly de Freitas Santos e Flávia Stefanello propõem reflexões referentes às relações entre escola e empresa e suas implicações. Destacam como a "colonização mercantil da educação" relaciona-se com a entrada de propagandas e da publicidade de grandes marcas no âmbito escolar. Nesse âmago, a escola deixa seu sentido como principal instituição de socialização. Os agentes escolares aderem a uma lógica mercantilista e capitalista nas relações, marcadas principalmente pela competitividade e pelo lucro.

No décimo quarto capítulo, de autoria de Carla Cristine Tramontina, Edson Regis de Jesus e Altair Alberto Fávero e intitulado “A democracia nas instituições de ensino para além da descentralização: possibilidade de resistência ao processo de mercantilização da educação", os autores abordam a questão das influências neoliberais nas instituições de ensino por meio do processo de descentralização. Uma prática bastante defendida para a democratização da educação, a descentralização tem permeado caminhos opostos ao induzir concepções de educação mercantilizada, tornando-se um produto adaptado aos desejos dos pais e dos educandos. A ideia de descentralização advém da adaptação pedagógica, que corresponde à articulação utilizada pelo neoliberalismo mediante subterfugios democráticos para alcançar a autonomia escolar. Essas implicações geram impactos negativos na formação para e com a democracia e a cidadania.

O décimo quinto capítulo, “La Educación formal como un claustro para las resistencias de los jóvenes en el contexto del neoliberalismo y la globalización", foi desenvolvido pelo pesquisador mexicano Edgar Flores Gómez. A pesquisa propõe conceituar termos como neoliberalismo, globalização e juventude no contexto atual mexicano. A 
juventude e a educação são vistas como símbolos de resistência e potência revolucionária. Em contrapartida, segundo o autor, a educação formal na contemporaneidade tornou-se de natureza individualista, com intento lucrativo e designada para uma parcela privilegiada da população.

O décimo sexto capítulo da obra, intitulado "A lógica empresarial na nova linguagem da escola: a narrativa do life long learning e a cilada do educar por competências", de autoria de Altair Alberto Fávero, Angélica Schmitt da Silva e Eduarda Cenci, discute acerca da narrativa do aprendizado ao longo de toda a vida (life long learning), por conta das demandas das profissões e tecnologias que se modificam constantemente. O fato é que a palavra "conhecimento" foi substituída por "competência", que está intimamente ligada ao saber prático e à técnica. Quando as competências tornam-se pedagogia, a escola incorpora uma lógica empresarial de funcionamento, a educação do sujeito passa a estar ligada a produtividade, eficácia e utilidade.

O décimo sétimo capítulo, designado como "A defesa da escola do tempo livre no cenário global", de autoria de Carmem Lúcia Albrecht da Silveira, Renata Cecilia Estormovski e Simone Zanatta Guerra, resgata o significado original de Skholé como lugar de ensino, reflexão, tempo livre e dedicado ao ócio, em defesa de uma educação democrática, universal e pública. Em contrapartida, na contemporaneidade, a escola perdeu seu sentido original, adotando uma lógica contábil e produtiva, descolada da formação humana.

No décimo oitavo capítulo, de autoria de Altair Alberto Fávero, Giovanna Dalquiavon e Thalia Leite de Faria, intitulado "Modernizar ou domar? A escola sob as rédeas da ideologia neoliberal", há uma aproximação entre o conceito de modernização citado por Laval (2004) e o conceito de domação segundo Masschelein e Simons (2013). Nesse cenário, a educação passa a ser domada pelas rédeas do neoliberalismo por meio de subterfúgios disfarçados de uma promessa de modernização, democratização e inovação da escola. Como uma reflexão desse impasse, os autores resgatam Mészáros (2008) com uma proposta de educação para além do capital.

O décimo nono capítulo, nomeado "A profissionalização como tática para domar o professorado: percepções do estudo da obra de Masschelein e Simons no projeto Vivências Docentes", foi escrito por Ana Lucia Kapczynski e Sindi Bones Böttker. A pesquisa concentrou-se em uma análise dos dados coletados no questionário que foi realizado em 
conjunto com um projeto de formação continuada, juntamente com 22 docentes de uma rede municipal de ensino. O problema central envolve a profissionalização como meio de domar os professores. O tempo que deveria ser designado ao ócio e ao contato com a experiência e o conhecimento passa a ser produtivo, restrito a conteúdos específicos e às competências.

De autoria de Ana Paula Pinheiro, o capítulo seguinte, intitulado "Avanços e entraves na formação democrática da escola pública brasileira: uma análise da politização e tecnologização a partir de Masschelein e Simons", aponta aparatos de revisitação histórica formativa do Brasil, propondo reflexões acerca dos processos democráticos e entraves relacionados com a educação pública brasileira. A autora retoma os conceitos de politização e tecnologização propostos por Masschelein e Simons (2014) como formas de domar a escola pública pelo desenvolvimento de habilidades e competências voltadas à empregabilidade.

Com o título "O neoliberalismo chega à escola: discursos produzidos e possibilidades de enfrentamento pela dimensão ético-estética", o vigésimo primeiro capítulo, escrito por Carina Copati, busca explanar contradições do discurso neoliberal na educação no âmbito escolar. Toma como exemplo o modelo estadunidense, que, por intermédio de fachadas de inovação, traz consigo uma lógica neoliberal produtivista, que provoca individualismo e competitividade. Em contrapartida, apresenta a necessidade de um modelo de escola que visa a recuperar os valores humanistas e sociais. À guisa de enfrentamentos, apresenta uma ressignificação da escola por meio do olhar sensível em conjunto com a compreensão da realidade e do mundo.

O vigésimo segundo capítulo, "Nas prateleiras do mercado: educação em oferta", desenvolvido por Bianca Possel e Laís Sincas Conte, contextualiza a mercantilização da escola em diferentes níveis de ensino. Em relação às educações básica e superior, abordam proposições referentes ao capitalismo acadêmico e, em seguida, fazem menção aos métodos de Educação a Distância (EaD). Constatam também a existência de uma visão mercadológica da educação como um produto que pode ser vendido e consumido.

Os textos presentes na coletânea auxiliam na compreensão da complexa relação entre neoliberalismo e educação, evocando que a educação vem sofrendo ataques constantes com o intuito de torná-la submissa ao modelo empresarial. Eles elucidam a questão da mercantilização do ensino e suas consequências em diferentes contextos, que clarificam de que forma a ideologia neoliberal na educação vem se tornando um fenômeno globalizado. Os 
textos, em sua maioria críticos da incursão da lógica neoliberal sobre a educação, demonstram diagnósticos comuns entre diversos países de uma redução drástica da educação como direito, como uma forma de individualização e socialização, como promotora da democracia e uma ampliação da educação como um produto de mercado, com finalidades estritamente econômicas e lucrativas, descoladas das graves iniquidades sociais. Por ser uma coletânea de caráter internacional, com a participação de pesquisadores de vários países e seus respectivos grupos de pesquisa, apresenta uma abordagem instigante daquilo que vem ocorrendo com a educação em âmbito global.

\section{Referência da obra resenhada}

FÁVERO, A. A; TONIETO, C.; CONSALTÉR, E. (org.). Leituras sobre educação e neoliberalismo. Curitiba: CRV, 2020.

\section{Outras referências}

LAVAL, C. A escola não é uma empresa: o neo-liberalismo em ataque ao ensino público. Londrina: Editora Planta, 2004.

MASSCHELEIN, J.; SIMONS, M. Em defesa da escola: uma questão pública. Tradução de Cristina Antunes. 2. ed. 3. reimp. Belo Horizonte: Autêntica Editora, 2018.

MÉSZÁROS, I. A educação para além do capital. 2. ed. São Paulo: Boitempo, 2008.

NUSSBAUM, M. C. El cultivo de la humanidad: una defensa clásica de la reforma en la educación liberal. Tradução de Juana Pailaya e Cubierta de Mario Eskenazi. Barcelona: Ediciones Paidós Ibérica, 2005.

Recebido em: 18/08/2020

Aprovado em: 26/03/2021

Publicado em: 15/06/2021 